\title{
A Comparative Study of Commercial Modified Celluloses as Bread Making Additives
}

\author{
María J. Correa and Cristina Ferrero \\ CIDCA-Facultad de Ciencias Exactas-UNLP-CCT La Plata (CONICET), La Plata, Argentina
}

\begin{abstract}
The effect of commercial modified celluloses: microcrystalline cellulose, carboxymethyl cellulose, and hydroxypropylmethyl cellulose on bread quality attributes and their potential protective effect with respect to bread staling were analyzed. Two levels of gums were assayed $(0.5$ and $1.5 \mathrm{~g} / 100 \mathrm{~g}$ flour). The best performance was obtained with carboxymethyl cellulose and hydroxypropylmethyl cellulose $\mathrm{F}$ $4 \mathrm{M}$ at both levels; these gums led to higher specific volumes and a better crumb texture as measured by texture profile analysis. In general, crumbs were softer, more cohesive, and resilient and exhibited lower chewiness values. Other gums like microcrystalline cellulose and hydroxypropylmethyl cellulose F50 did not improve bread quality on the same extent. Mechanical spectra obtained by dynamic mechanical analysis assays indicated a marked change in molecular mobility when carboxymethyl cellulose was present. Bread staling was evaluated by texture profile analysis, moisture loss, and calorimetric assays. Gums did not avoid retrogradation and even exhibited an accelerating effect, probably due to changes in water retention and migration during storage. However, in most cases, final crumb hardness in samples with hydrocolloids was lower than that in the control sample.
\end{abstract}

Keywords: Wheat bread, Modified celluloses, Texture, Staling, Retrogradation.

\section{INTRODUCTION}

Cellulose is the most abundant polysaccharide in nature, constituting the principal component of all vegetation; it reaches up to the third part of plant dry material. This polymer is also the most important renewable resource. Together with hemicelluloses, pectins, and lignin, it plays a significant role in plant structure, forming the cell walls. It is present up to $50 \%$ in woody materials, up to $98 \%$ in cotton linters, and about $30 \%$ in other agricultural residues, such as corn stalks and cobs and wheat straw. ${ }^{[1]}$

From a structural point of view, cellulose is a linear polysaccharide consisting of glucose residues linked together by $\beta-1,4$ glycoside bonds. Because of their high molecular weight, linear conformation and the hydroxyl groups geometry, these molecules have a strong tendency to form hydrogen-bonding thus rendering rigid crystalline regions. This property can explain the high insolubility of native cellulose and also their stability with respect to chemical or enzymes attacks.

Received 10 May 2013; accepted 22 November 2013.

Address correspondence to María J. Correa and Cristina Ferrero, CIDCA—Facultad de Ciencias Exactas-UNLP-CCT La Plata (CONICET), 47 Y 116, La Plata 1900, Argentina. E-mail: mjcorrea@biol.unlp.edu.ar; cferrero@biol.unlp.edu.ar 
Because of this resistance to enzymatic hydrolysis, cellulose can be considered as dietary fiber, since it is not digested nor absorbed in the small intestine. ${ }^{[2]}$ As a food additive, native cellulose has only limited use due to its insolubility. Chemical modifications, particularly the substitution with different functional groups, can change cellulose properties allowing a more extended application. The more spread cellulose derivatives in the food industry are ethers in which substitution upon one or more of the three available hydroxyl groups in each anhydroglucose monomer have been performed with alkyl or hydroxyalkyl groups. The substitution facilitates chain separation and allows further hydration and solubilization. The type and degree of substitution determines diverse functional properties. ${ }^{[1]}$ The more important derivatives are sodium carboxymethylcellulose (CMC), methylcellulose (MC), hydroxypropylcellulose (HPC), and hydroxypropylmethylcellulose (HPMC). Another derivative is the microcrystalline cellulose (MCC) obtained by acid hydrolysis. This reaction cleavages the non-crystalline zones and allows concentration of the crystalline ones. Uses of modified celluloses vary according to their structure. MCC colloidal dispersions are used as thickeners, ${ }^{[3]}$ for ice crystal control, caloric reduction and fiber addition, ${ }^{[4]}$ and foam and emulsion stabilization. ${ }^{[5]} \mathrm{CMC}$ can be used as a stabilizer in ices and milk beverages, ${ }^{[6]}$ for viscosity development and suspension of solids in batters and coatings, ${ }^{[7,8]}$ and as a thickener in pie fillings. ${ }^{[9]}$ HPMCs have the unique property of gel forming by heating due to their more hydrophobic character. They are applied in film formation, ${ }^{[10]}$ as stabilizers in salad dressings, as oil barrier in fried foods, ${ }^{[11]}$ and in frozen foods for inhibiting moisture losses and ice crystal growth. ${ }^{[12]}$ Furthermore, HPMC is widely used in gluten-free products. ${ }^{[13]}$

Modified celluloses can be also applied in bakery products. There have been reported beneficial effects of HPMCs on specific volume and crumb texture of common bread as well as on shelf life of partially baked bread. ${ }^{[14,15]}$ It has been reported that HPMCs can interact with gluten proteins ${ }^{[16]}$ and with starch affecting gelatinization. ${ }^{[17]}$ Carboxymethylcellulose (CMC) has been studied by several authors as an improver for fresh or frozen dough and in fiber enriched fresh breads. ${ }^{[18-20]}$ However, information about the effect of microcrystalline cellulose (MCC) on bread products is scarce. In a previous work, ${ }^{[21]}$ a comparative study of the effect of different modified celluloses on wheat dough characteristics has been performed. Salt was found to be relevant for the quality of gluten network, depending on the type of cellulose. A more stable protein matrix was obtained with $\mathrm{CMC}$ in the presence of salt $(\mathrm{NaCl})$. On the other hand, with more hydrophobic modified celluloses like HPMCs a less stable network was observed when salt was added. Gum addition also affected textural attributes of dough, such as adhesiveness, hardness, and consistency, and an increase in viscous behavior was observed by rheometric assays when these hydrocolloids were added. The degree of these effects was strongly dependent on salt presence. The objectives of the present work were: (a) to compare the effect of commercial modified celluloses (MCC, CMC, and HPMC) on bread quality attributes; and (b) to evaluate their potential protective effect with respect to bread staling.

\section{MATERIALS AND METHODS}

\section{Materials}

Wheat commercial flour of standard quality provided by Molino Campodónico S.A. (La Plata, Argentina) was used for dough preparation. Flour composition was as follows: proteins, $11.4 \mathrm{~g} / 100 \mathrm{~g}$ flour (Kjeldahl factor $=5.7$ ); lipids, $1.4 \mathrm{~g} / 100 \mathrm{~g}$ flour; moisture, $14.2 \mathrm{~g} / 100 \mathrm{~g}$ flour; and ash, $0.678 \mathrm{~g} / 100 \mathrm{~g}$ flour. Alveographic parameters of flour were: $P=96 \mathrm{~mm} \mathrm{H}_{2} \mathrm{O}, L=93 \mathrm{~mm}, W=$ $32610^{-4} \mathrm{~J}$, and the falling number (FN) was $486 \mathrm{~s}$. The modified celluloses employed were: microcrystalline cellulose (MCC; FMC Biopolymer, Philadelphia, PA, USA), carboxymethyl cellulose (CMC; Latinoquímica Amtex S.A., Argentina), and two different types of hydroxypropylmethylcellulose (HPMC F 4 M and HPMC F 50, Dow Chemical Company, USA). HPMC F 4 M has a degree 
of substitution with methoxyl groups of $29.3 \%$ and a degree of substitution with hydroxypropyl groups of $6.0 \%$. For HPMC F 50, these values are 28.6 and $5.4 \%$, respectively. Commercial designations for HPMCs are based on viscosity values for $2 \%$ gum solutions in water at $20^{\circ} \mathrm{C}$, according to ASTM method D1347. ${ }^{[22]}$ For the types used in this work, viscosities were $4477 \mathrm{mPa} . \mathrm{s}$ for HPMC F $4 \mathrm{M}$ and $46 \mathrm{mPa} . \mathrm{s}$ for HPMC F 50. Commercial MCC contains $12 \% \mathrm{w} / \mathrm{w}$ of CMC for a better dispersion. Distilled water and commercial salt $(\mathrm{NaCl})$ were used to prepare dough.

\section{METHODS}

\section{Breadmaking}

\section{Dough formulation}

Dough formulation on $100 \mathrm{~g}$ flour basis was compressed yeast 3.0\% (Calza, Argentine), salt $2.0 \%$, modified celluloses: $0.25,0.5,1.0$, and $1.5 \%$ and water according to farinograph absorption of each formulation. Dough without modified celluloses was used as the control. Batches of approximately $650 \mathrm{~g}$ were prepared in a planetary kneader (Kenwood, Italy). Dry ingredients were premixed and the yeast was dissolved in part of the added water. Mixing times were fixed according to development times obtained from farinograph assays.

\section{Fermentation times}

For determining optimum fermentation time for each formulation, dough prepared as described above was divided into pieces $(50 \mathrm{~g})$, placed at the bottom of a graduated probe, and were left in a $30^{\circ} \mathrm{C}$ chamber (Brito Hnos, Argentine). Assays were performed by duplicates. The increase in volume $(\Delta V)$ was defined as the difference between the volume at a certain time and the initial volume and it was registered as function of time. Measurements were performed until the highest increase in volume $\left(\Delta V_{\max }\right)$ was obtained. In Fig. 1a, a fermentation curve is showed and $\Delta V_{\max }$ is indicated. Values were fitted with an exponential equation (Chapman) including three parameters (Eq. 1):

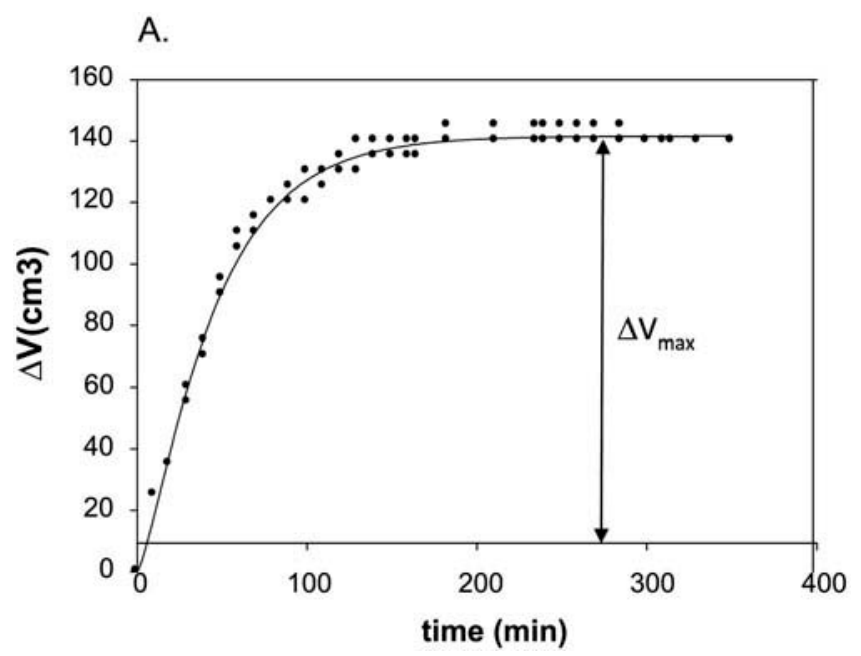

FIGURE 1 (A) Typical fermentation curve where $\Delta V_{\max }$ is indicated. 
B.

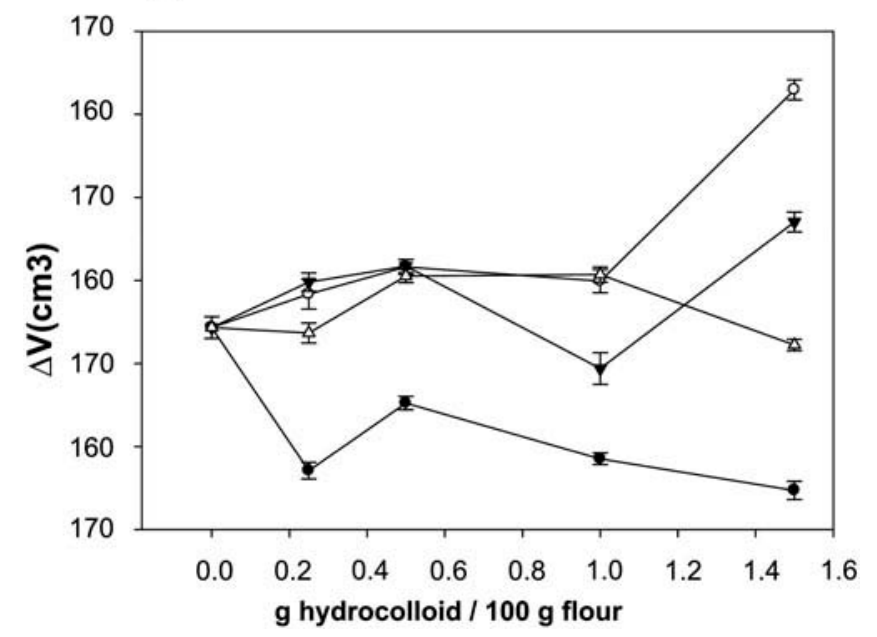

FIGURE 1 (B) Maximum increment of fermentation volume as obtained from Eq. (1). Symbols: (O) CMC, MCC, $(\triangle)$ HPMC F 50, ( $)$ HPMC F 4 M. Bars indicate standard deviation for the parameter " $a$ " $\left(\Delta V_{\max }\right)$ in Eq. (1).

$$
\Delta V=a *(1-\exp (-b * t))^{c},
$$

where $a=\Delta V_{\max }$, optimum fermentation time for each formulation was defined as the time required to reach up to three quarts of $\Delta V_{\max }$.

\section{Breadmaking process}

For French-type bread preparation, two levels of hydrocolloids were assayed. After kneading, dough was left to rest for $10 \mathrm{~min}$ at room temperature, sheeted four times, and left to rest again. Then, it was divided into 90 -g pieces. Each portion was rounded by hand, left to rest for $10 \mathrm{~min}$, and then shaped into bread loaves by means of a sheeter molder. These pieces were proofed at $30^{\circ} \mathrm{C}$ according to the optimum fermentation time and baked in a convection oven for $26 \mathrm{~min}$ at $210^{\circ} \mathrm{C}$. After at least $3 \mathrm{~h}$, breads were packaged into plastic bags and stored for 1 and 3 days at $20^{\circ} \mathrm{C}$.

\section{Bread characterization}

Specific volume. After cooling, bread pieces were weighted and each volume was determined by rapeseed displacement. The specific volume was calculated as volume/piece weight. Measurements were performed by 15 replicates.

Crumb moisture. It was determined on fresh bread and after 1 and 3 days of storage at $20^{\circ} \mathrm{C}$. The assay was performed according the AACC 44-19 method. ${ }^{[23]}$

Crust color. It was measured using a colorimeter (Chroma Meter CR-400C, Minolta, Osaka, Japan). The Hunter scale parameters were determined: L (lightness, ranging from 0 to 100, from black to white), a (positive values indicating redness and negative values, greenness), and b (positive values indicate yellowness and negative values, blueness).

Crumb image analysis. Crumb grain characteristics of bread were assessed using a digital image analysis (DIA) system. Images of the center of each slice were previously acquired at a 
resolution of 350 dots per inch with a HP scanner 4070 model. Images were binarized using Image $\mathrm{J} 1.43 \mathrm{u}$ software. The crumb grain characteristics studied were mean cell area $\left(\mathrm{cm}^{2}\right)$, circularity, perimeter $(\mathrm{cm})$, and cell to total area ratio (or void fraction).

Crumb texture profile analyses. Texture profile analysis (TPA) of bread slices was performed on fresh bread and after 1 and 3 days of storage at $20^{\circ} \mathrm{C}$. From the middle part of each bread piece, two slices of $2 \mathrm{~cm}$ thickness were obtained. A texture analyzer TA.XT2i (Stable Micro Systems, Surrey, UK) equipped with a $25-\mathrm{kg}$ load cell was used to perform the TPA of crumb. The slices were subjected to a double compression cycle up to $40 \%$ of the original height using a 2.5 -cm diameter cylindrical probe and $0.5 \mathrm{~mm} \mathrm{~s}^{-1}$ crosshead speed. Fifteen slices for each formulation were tested. The parameters determined were hardness, cohesiveness, consistency, springiness, resilience, and chewiness. Hardness is defined as the maximum force registered during the first compression cycle. Cohesiveness was determined as the ratio between the positive area of the second cycle and the positive area of the first cycle. Consistency was calculated as the area of the first peak plus the area of the second peak. Springiness was calculated as the distance between the beginning and the peak of the second cycle divided by the corresponding distance of the first cycle. Resilience or instantaneous elasticity was calculated as the area during the withdrawal of the first compression, divided by the area up to the maximum of the first cycle. Chewiness is calculated as the product of Hardness * Cohesiveness * Springiness.

Crumb dynamic mechanical analysis (DMA). Crumb samples for DMA assays were prepared following the technique described by Ribotta and Le Bail. ${ }^{[24]}$ Crumb pieces of approximately $1 \mathrm{~cm}$ thick were obtained from the central portion of each bread and then compressed up to $90 \%$ of the initial height in a texture analyzer TA.XT2i (Stable Micro Systems, Surrey, UK). Samples were molded to slabs of $60 \mathrm{~mm}$ long, $15 \mathrm{~mm}$ wide, and approximately $3 \mathrm{~mm}$ thick. The slabs were wrapped with a plastic film to avoid dehydration and then they were frozen at $-18^{\circ} \mathrm{C}$ till measurement. A Q 800 dynamic mechanical analyzer (TA Instruments, USA) was used with dual cantilever geometry. The equipment was operated in a controlled force mode to obtain the linear viscoelastic range and in the multi-frequency controlled strain mode to measure dynamic viscoelastic properties of bread crumb samples. The measurements were performed at an amplitude of $15 \mu \mathrm{m}$ within the linear viscoelastic range. Samples were heated from -100 to $40^{\circ} \mathrm{C}$ at $5^{\circ} \mathrm{C} / \mathrm{min}$. Storage modulus $\left(E^{\prime}\right)$, loss modulus $\left(E^{\prime \prime}\right)$, and loss tangent $(\tan \delta)$ were obtained as a function of three frequencies: 1 , 5 , and $10 \mathrm{~Hz}$. The assay was performed in duplicate.

\section{Bread Staling}

Breads were stored at room temperature in plastic bags for 1 and 3 days. At each storage time, crumb moisture and texture parameters were obtained as described above.

\section{Crumb moisture loss}

Moisture loss was calculated as the difference between moisture at the 3rd day with respect to moisture of fresh bread (day 0) divided by moisture at day 0 .

\section{Differential scanning calorimetry}

Calorimetric assays were performed to evaluate amylopectin retrogradation in control dough and in doughs with modified celluloses at $1.5 \%$. A TA Q100 calorimeter (TA Instruments, USA) was used to obtain the thermograms. Small aliquots of dough (approximately $10 \mathrm{mg}$ ) exactly weighed were put into the pans and then these were hermetically sealed. Samples were heated from 5 to $105^{\circ} \mathrm{C}$ at $10^{\circ} \mathrm{C} / \mathrm{min}$, simulating the baking process, and then allowed to rest at room temperature for 3 and 7 days. At each storage time a sample was heated from 5 to $140^{\circ} \mathrm{C}$ at $5^{\circ} \mathrm{C} / \mathrm{min}$. Onset, peak, 
and final temperature and retrogradation enthalpies were measured. Also, the retrogradation index (RI) was calculated according to the following equation:

$$
\mathrm{RI} \%=\frac{\Delta \mathrm{H}_{\text {after storage }}}{\Delta \mathrm{H}_{\text {gelatinization }}} * 100 .
$$

For each formulation, a run of a sample without storage was performed as a control.

\section{Statistical Analysis}

To discriminate among means, Bonferroni's multiple comparison procedure was applied at $95 \%$ confidence level. Statgraphics Plus software was used.

\section{RESULTS AND DISCUSSION}

\section{Optimum Fermentation Times}

At the maximum level of gum, doughs that reached up to greater volumes also required longer fermentation times. In Fig. 1b, maximum increments $\left(\Delta V_{\max }\right)$ attained are plotted as a function of the additive level. Doughs with MCC exhibited a lower $\Delta V_{\max }$ and shorter fermentation times than the control sample. This could be related to the fact that MCC particles are not soluble; thus, it could act as filler in the gluten matrix with loss of elasticity. On the other hand, doughs with CMC reached up to higher volumes than the control. With CMC of $1.5 \%$, the highest $\Delta V_{\max }$ was obtained. Doughs with both HPMCs at the lowest levels showed a behavior similar to control dough. When using HPMC F 4 M 1.5\%, only a slight volume increase was observed compared with the sample without gum. Rosell et al. ${ }^{[14]}$ reported that dough stability during fermentation was improved by the addition of HPMC. Besides, a better gas retention was observed when HPMC was used. CMC was the gum that most improved dough behavior during fermentation since it allowed attaining higher fermentation volumes. However, this could not be correlated with a higher farinographic stability, reported in a previous work. ${ }^{[21]}$ Taking into account these results, two levels for each hydrocolloid were applied to analyze bread quality: the lowest level at which no significant differences were detected among most formulations and a higher level at which each modified cellulose had a distinct effect on dough. Selected levels were 0.5 and $1.5 \%$. At $0.5 \%$, most gums exhibited a maximum volume slightly higher than the control. As seen in Fig. 1b, at $1.5 \%$ hydrocolloid level, samples with HPMC F $4 \mathrm{M}$ and CMC showed a $\Delta V_{\max }$ much higher than the control $(147.0,162.9$, and $134.3 \mathrm{~cm}^{3}$, respectively), HPMC F $50 \Delta V_{\max }$ was similar to control one $\left(132.2 \mathrm{~cm}^{3}\right)$, and that of MCC was inferior to it $\left(114.7 \mathrm{~cm}^{3}\right)$. The inferior performance of MCC can be probably attributed to the insolubility of this gum; dispersed MCC particles could disrupt gluten matrix rendering a less elastic dough.

\section{Fresh Bread Quality}

Among the quality attributes of bread, a specific volume is highly dependent on gluten network quality and its ability to retain the carbon dioxide produced during fermentation. Specific volumes of breads are shown in Fig. 2. CMC and HPMC F $4 \mathrm{M}$ at both levels allowed to significantly increase the specific volume. On the other hand, no significant differences were found among breads containing MCC and control breads. This is in accordance with the trend observed in fermentation stage. Breads with HPMC F 50 at $1.5 \%$ had no significant differences with respect to control, whereas at the lowest level of hydrocolloid, a higher specific volume was obtained. In the case of CMC and 


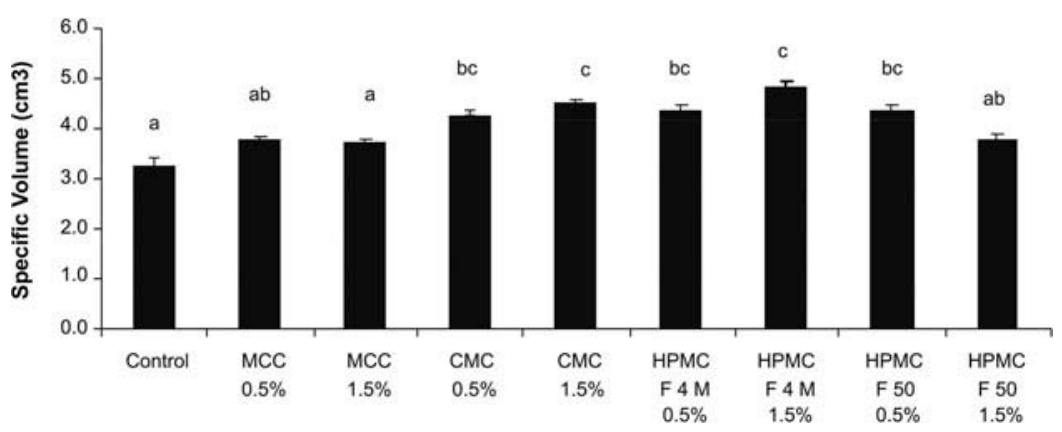

FIGURE 2 Specific volume of bread. Different letters indicate significant differences $(p<0.05)$. Error bars correspond to standard error.

HPMC F 4 M, a tendency was observed to higher volumes with increasing concentration of cellulose. These tendencies had not been reflected in farinographic stability, since this parameter was not affected or diminished by the presence of celluloses. ${ }^{[21]}$ These beneficial effects of HPMC and CMC are in agreement with those reported by other authors. ${ }^{[14,19,25]}$

Crust color is another quality parameter that highly affects bread acceptance. In general, this attribute was not affected by cellulose addition. L values ranged from 56.5 to 63.3 , a ranged from 9.7 to 13.1 , and b ranged from 32.5 to 36.5 . In most cases, no significant differences with respect to control were detected, and though in some cases color differences could be distinguished by the colorimeter, they were not detectable for the human eye. Crumb appearance was dependent on the number and size of alveoli. For a high quality bread, alveoli should be numerous and uniformly sized and distributed. In this case, no significant differences were found in the crumb grain characteristics among the different samples (Table 1). In spite of the differences found in the specific volume, the percentage of void area (which is related to a more aerated crumb) was not significantly different among samples nor the mean area of alveoli. However, a trend to higher values of void area was found in samples with $1.5 \% \mathrm{CMC}$, and to less aerated crumb in samples with MCC at $0.5 \%$. One reason for this high uniformity among samples is the fact that specimens for digital analysis were taken from the central region of each slice, which is the more aerated part. A more compact crumb was found in the bottom and near the surface of the bread. Taking into account this limitation, a specific volume gives a more precise approach to bread quality.

TABLE 1

Crumb appearance

\begin{tabular}{|c|c|c|c|c|}
\hline Sample & $\begin{array}{c}\text { Mean cell area } \\
\left(\mathrm{cm}^{2}\right)\end{array}$ & $\%$ Void & $\begin{array}{l}\text { Perimeter } \\
\quad(\mathrm{cm})\end{array}$ & $\begin{array}{l}\text { Circularity } \\
\text { (adim) }\end{array}$ \\
\hline Control & $0.013 \pm 0.003^{\mathrm{ab}}$ & $43.4 \pm 3.2^{\mathrm{ab}}$ & $0.67 \pm 0.06^{\mathrm{b}}$ & $0.40 \pm 0.04^{\mathrm{a}}$ \\
\hline MCC $0.5 \%$ & $0.014 \pm 0.003^{\mathrm{ab}}$ & $40.9 \pm 1.1^{\mathrm{a}}$ & $0.67 \pm 0.06^{\mathrm{b}}$ & $0.42 \pm 0.01^{\mathrm{a}}$ \\
\hline MCC $1.5 \%$ & $0.012 \pm 0.001^{\mathrm{ab}}$ & $42.6 \pm 3.3^{\mathrm{ab}}$ & $0.64 \pm 0.03^{\mathrm{ab}}$ & $0.41 \pm 0.05^{\mathrm{a}}$ \\
\hline CMC $0.5 \%$ & $0.011 \pm 0.001^{\mathrm{a}}$ & $42.8 \pm 2.5^{\mathrm{ab}}$ & $0.57 \pm 0.05^{\mathrm{a}}$ & $0.45 \pm 0.03^{\mathrm{a}}$ \\
\hline CMC $1.5 \%$ & $0.014 \pm 0.001^{\mathrm{ab}}$ & $45.8 \pm 2.7^{\mathrm{b}}$ & $0.68 \pm 0.04^{\mathrm{b}}$ & $0.42 \pm 0.02^{\mathrm{a}}$ \\
\hline HPMC F 4 M $0.5 \%$ & $0.014 \pm 0.001^{\mathrm{ab}}$ & $42.1 \pm 2.1^{\mathrm{ab}}$ & $0.67 \pm 0.05^{\mathrm{b}}$ & $0.41 \pm 0.03^{\mathrm{a}}$ \\
\hline HPMC F 4 M $1.5 \%$ & $0.014 \pm 0.002^{\mathrm{b}}$ & $43.1 \pm 1.1^{\mathrm{ab}}$ & $0.67 \pm 0.07^{\mathrm{b}}$ & $0.43 \pm 0.02^{\mathrm{a}}$ \\
\hline HPMC F $500.5 \%$ & $0.015 \pm 0.002^{\mathrm{b}}$ & $42.7 \pm 1.5^{\mathrm{ab}}$ & $0.67 \pm 0.03^{b}$ & $0.43 \pm 0.02^{\mathrm{a}}$ \\
\hline HPMC F $501.5 \%$ & $0.012 \pm 0.002^{\mathrm{ab}}$ & $41.2 \pm 2.3^{\mathrm{a}}$ & $0.64 \pm 0.05^{\mathrm{ab}}$ & $0.43 \pm 0.02^{\mathrm{a}}$ \\
\hline
\end{tabular}

\pm SD. Different letters indicate significant differences within the same column. 

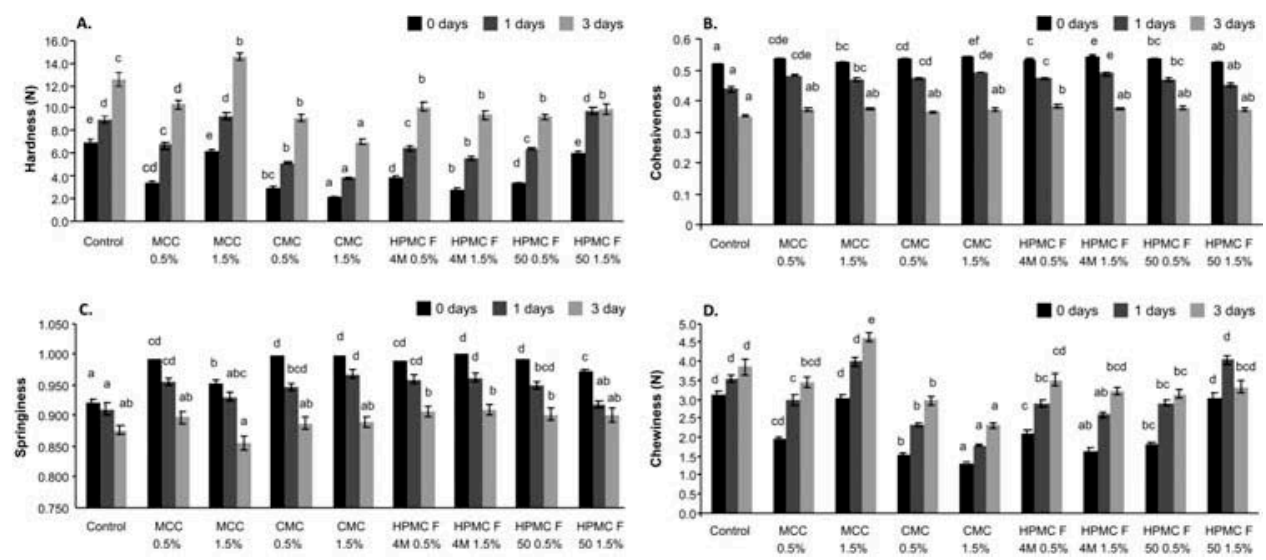

FIGURE 3 Crumb hardness (A), cohesiveness (B), springiness (C), and chewiness (D) for fresh bread and for bread stored 1 day and 3 days at $20^{\circ} \mathrm{C}$. Different letters within the same group of bars indicate significant differences $(p<$ 0.05). Error bars correspond to standard error.

Instrumental texture profile analysis (TPA) of fresh bread crumb showed that the addition of MCC and HPMC F 50 at $1.5 \%$ level led to similar hardness than the control sample (Fig. 3a). In all other cases crumbs were softer than the control, particularly in the case of CMC at $1.5 \%$. It is noteworthy that the increment on gum level did not cause the same effect in all cases. It led to softer crumbs in the case of CMC and HPMC F 4 M, but the increase in concentration of MCC and HPMC F 50 led to harder crumbs.

Cohesiveness increased with the addition of hydrocolloids in all cases (Fig. 3b). This is a positive effect since more cohesive crumbs are less susceptible to disintegration. Springiness (elasticity) is a positive attribute in crumb and it was improved by the addition of gums (Fig. 3c). Resilience (instant elasticity) of fresh bread was also increased by the addition of gums, ranging from 0.436 to 0.496, while the value for the control sample was 0.363 (results not shown). This indicates that hydrocolloids contribute to improve the recovery after a deformation. Chewiness showed the same trend than hardness, with lower values for CMC and HPMC F 4 M samples (Fig. 3d). The highest levels of these gums had a positive effect, decreasing this parameter. On the other hand, with MCC and HPMC F 50, the highest level of hydrocolloid led to higher values in chewiness.

According to Attenburrow et al., ${ }^{[26]}$ the Young's modulus $(E)$ of a food sponge as bread crumb is a function of the Young's modulus of the cell walls $\left(E_{s}\right)$ and the relative density of the bread crumb (ratio between bulk density of foam and the density of cell wall material) according to the expression: $E \infty E_{s}\left[\rho / \rho_{s}\right]^{2}$. By analyzing the specific volume and the crumb hardness it is observed that, in general, samples with higher specific volumes led to softer crumbs. This was confirmed by the correlation coefficient (0.7). However, samples with the same specific volume CMC (both levels), HPMC F 4 M (both levels), and HPMC F 50 (at 0.5\%) exhibited significant differences in hardness (the lower values corresponded to CMC and HPMC F $4 \mathrm{M}$ at $1.5 \%$ level). If the bulk density is the same, differences in global Young modulus should be attributed to density and Young modulus of the alveoli walls according to the above expression. More density and/or less elasticity (a lower Young modulus) of cell wall materials would be related to a less elastic crumb. In a previous work, it was reported that hydrocolloids led to softer doughs, and disruption of gluten networks was observed in some cases. ${ }^{[21]}$

Mechanical spectrum of control and CMC bread crumbs are shown in Fig. 4a and 4b, respectively. In all cases a decrease in the storage modulus and an increase of $\tan (\delta)$ was observed indicating a more viscous behavior during heating. The loss modulus exhibits two or three peaks depending on 
A.

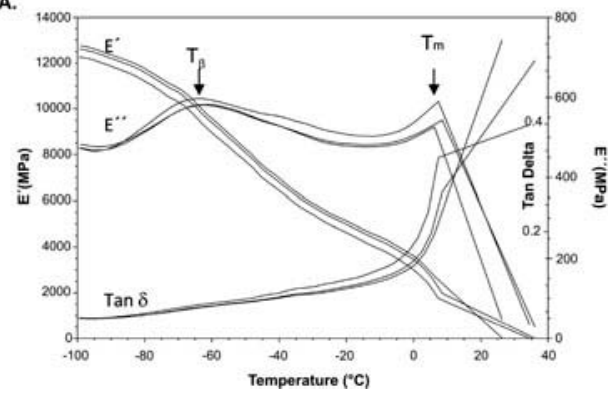

B.

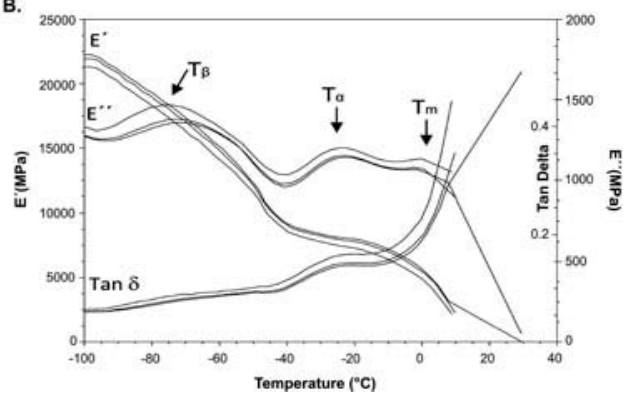

FIGURE 4 Mechanical spectrum of fresh bread crumb by DMA: (A) control, (B) CMC 1.5\%. Tan $\delta$, storage, and loss moduli are shown.

the sample. The peak near to $0^{\circ} \mathrm{C}$ is due to ice melting $\left(T_{m}\right)$, the peak near to $-30^{\circ} \mathrm{C}$ is attributed to $\alpha$ relaxation that is associated with the glass transition, and the peak near to $-70^{\circ} \mathrm{C}\left(T_{\beta}\right)$ is associated to a $\beta$-relaxation below the glass transition. ${ }^{[27]}$ The $\beta$-relaxation has been attributed to localized molecular motion in the glassy state, particularly with side chains rotations or with conformational changes of the main chain. ${ }^{[28,29]}$

In samples with $\mathrm{CMC}$ or MCC, the peak corresponding to glass transition $\left(T_{\alpha}\right)$ was observable and could be measured. A small peak was observed in the case of HPMC F $4 \mathrm{M}$ and this transition was not noticeable in the control sample nor when HPMCF F 50 was added (results not shown). On the other hand, the $\beta$-relaxation was present in all samples indicating that matrix in the glass state exhibits rotational mobility in a higher or lower degree. The type of mechanical spectrum found in CMC samples, with more pronounced peaks, is indicating a less rigid matrix; this fact could affect the stiffness of alveoli walls.

\section{Effect of Storage}

Table 2 shows crumb moisture of fresh and stored bread. In spite of the fact that no differences were found in bread with celluloses, with respect to control for the first day, increased water retention was observed during storage in breads with additives. This fact is beneficial for breadmaking since water retention contributes to preserve crumb texture for longer periods.

TABLE 2

Crumb moisture in fresh bread and after 1 and 3 days in storage

\begin{tabular}{|c|c|c|c|c|}
\hline Sample & Day 0 & Day 1 & Day 3 & $\operatorname{Loss}(\%)$ \\
\hline Control & $44.3 \pm 0.5^{\mathrm{bcd}}$ & $42.4 \pm 0.5^{\mathrm{a}}$ & $37.8 \pm 0.6^{\mathrm{a}}$ & 14.6 \\
\hline MCC $0.5 \%$ & $43.0 \pm 0.2^{\mathrm{a}}$ & $42.7 \pm 1.1^{\mathrm{ab}}$ & $38.3 \pm 1.0^{\mathrm{ab}}$ & 10.9 \\
\hline MCC $1.5 \%$ & $43.6 \pm 0.3^{\mathrm{ab}}$ & $42.6 \pm 0.5^{\mathrm{a}}$ & $40.7 \pm 0.5^{\mathrm{cd}}$ & 6.8 \\
\hline CMC $0.5 \%$ & $44.6 \pm 0.1^{\mathrm{d}}$ & $43.2 \pm 0.5^{\mathrm{abc}}$ & $40.6 \pm 0.5^{\mathrm{cd}}$ & 9.0 \\
\hline CMC $1.5 \%$ & $44.3 \pm 0.3^{\mathrm{cd}}$ & $43.7 \pm 0.8^{\mathrm{abc}}$ & $42.1 \pm 0.5^{\mathrm{d}}$ & 9.5 \\
\hline HPMC F 4 M $0.5 \%$ & $44.7 \pm 0.5^{\mathrm{d}}$ & $44.5 \pm 0.1^{\mathrm{bc}}$ & $40.2 \pm 0.8^{\mathrm{cd}}$ & 10.0 \\
\hline HPMC F 4 M $1.5 \%$ & $44.6 \pm 0.3^{\mathrm{d}}$ & $44.5 \pm 0.3^{c}$ & $39.9 \pm 1.0^{\mathrm{bc}}$ & 10.6 \\
\hline HPMC F $500.5 \%$ & $43.6 \pm 0.5^{\mathrm{abc}}$ & $43.5 \pm 0.9^{\mathrm{abc}}$ & $40.9 \pm 0.2^{\mathrm{cd}}$ & 6.1 \\
\hline HPMC F $501.5 \%$ & $44.3 \pm 0.8^{\mathrm{d}}$ & $44.0 \pm 1.2^{\mathrm{c}}$ & $40.9 \pm 1.0^{\mathrm{cd}}$ & 7.7 \\
\hline
\end{tabular}

\pm SD. Different letters indicate significant differences within the same column. 
During storage, crumb hardness was increased (Fig. 3a). For the control sample, the increment in hardness at the first day of storage was $29.9 \%$. When hydrocolloids were used, increments ranged from 50.6 to 99.5 . At day 3, increments were between 65.5 and $241.2 \%$, while for control without gum the increment was $81.5 \%$. The lowest rate in increasing hardness was observed for MCC and HPMC F 50 at $1.5 \%$. This indicates that celluloses were not efficient in preventing crumb hardening induced by retrogradation and they even promoted them.

During storage cohesiveness is partially lost, and at day 3 no significant differences were observed between samples without and with hydrocolloids. Percent decrease after 3 days of storage ranged from 27.9 to $32.1 \%$ (Fig. 3b). At the 3rd day of storage, resilience of samples with hydrocolloids diminished up to $61.7 \%$ with respect to day 0 , while for control bread, the diminution was $50.5 \%$. Elasticity (springiness) exhibited a similar trend, diminishing with storage but in a lesser extent than resilience (Fig. 3c). At the 3rd day of storage, a decrease in springiness in the presence of hydrocolloids reached up to $19.6 \%$ with respect to day 0 , while control diminished only by $4 \%$ with respect to day 0 .

Chewiness exhibited a trend to increase during storage (Fig. 3d). As chewiness is the product of hardness $\times$ cohesiveness $\times$ springiness, but the degree of variation in these three attributes is not the same (hardness increases in a higher degree), the global result is an increase of chewiness. These results indicate that hydrocolloids can render softer and more elastic and resilient crumbs but they also would promote the partial loss of these characteristics during storage. However, since initial values for these attributes are improved in the presence of gums, the final texture of bread with hydrocolloids results are more acceptable than that of the control sample. ${ }^{[14,30,31]}$

These textural changes in crumb during storage can be related to starch retrogradation. As the presence of hydrocolloids can lead to less rigid matrices and increased water retention, diffusion dependent processes, such as starch retrogradation, could be favored.

In Table 3, amylopectin retrogradation parameters after 3 and 7 days of storage are shown. Peak and endset temperatures were not significantly different with respect to control except for MCC and CMC samples that showed a higher temperature. At the 3rd day, the more pronounced differences with respect to the control were found for HPMC F $4 \mathrm{M}$, particularly in enthalpy value and onset temperature. In general, after 7 days of storage, no significant differences with respect to control were found in temperatures nor in enthalpy. However, enthalpy value for the HPMC F 4 M sample remains the highest.

RI has been used by several authors to compare the retrogradation process among samples. ${ }^{[31,32]}$ Breads with HPMC F 4 M exhibited the highest RI, whereas no significant differences were found for other samples with respect to control at the same time of storage. When RI\% was compared between the $3 \mathrm{rd}$ and the 7th day of storage an increment was found in the case of control, MCC, and HPMC F 50 samples. These results indicate that, in general, the incidence of modified celluloses on amylopectin retrogradation is low. Since hydrocolloids could not directly interact with amylopectin that remains inside the granule, their incidence on retrogradation is related to the surrounding matrix, leading to textural changes.

\section{CONCLUSIONS}

Modified celluloses can change fresh bread attributes leading to higher volumes and softer crumbs. These can be related to the type of gluten-hydrocolloid matrix that is formed. Particularly, this effect was observed with CMC and HPMC F 4 M (higher specific volume, better crumb texturesofter and more cohesive and resilient crumbs). Other gums, like MCC and HPMC F50, did not improve bread quality to the same extent. Concerning bread staling, gums had an accelerating effect on retrogradation, probably due to changes in water retention and water migration ability during storage. However, after storage final hardness was lower in most crumbs, and positive characteristics, 


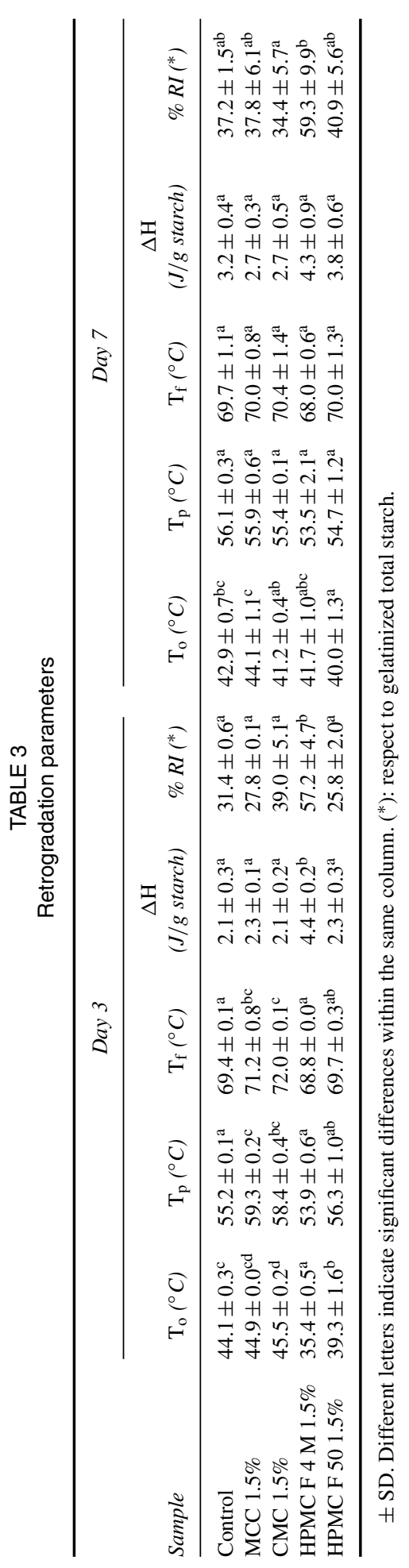


such as cohesiveness, resilience, and elasticity, were better maintained, indicating a beneficial effect of modified celluloses.

\section{ACKNOWLEDGMENTS}

The authors gratefully acknowledge the Dow Chemical Co. and Latinoquímica Amtex (Argentina) for gum donations. The authors would also like to thank Dario Cabezas for his assistance in improving the figures.

\section{FUNDING}

The authors wish to acknowledge FONCYT, CONICET, and Universidad Nacional de La Plata (Argentina) for the financial support for this study.

\section{REFERENCES}

1. Glicksman, M. Cellulose gums-introduction. In: Food Hydrocolloids, Vol. I; Glicksman, M.; Ed.; CRC Press, Inc.: Boca Raton, FL, 1982; 3-8.

2. Prosky, L. What is fibre? Current controversies. Trends in Food Science and Technology 1999, 10, 271-275.

3. Yaginuma, Y.; Kijima, T. Effects of microcrystalline cellulose on suspension stability of cocoa beverage. Journal of Dispersion Science and Technology 2006, 27, 941-948.

4. Abozeid, W.M.M.; Salama, M.F.; Moawad, R.K. Utilization of fat replacer in the production of reduced cakes and cookies. Australian Journal of Basic and Applied Sciences 2011, 5 (12), 2833-2840.

5. Chen, J.; Yan, S.; Ruan, J. A study on the preparation, structure, and properties of microcrystalline cellulose. Journal of Macromolecular Science, Part A: Pure and Applied Chemistry 1990, 33, 1851-1862.

6. Janhøj, T.; Frøst, M.B.; Ipsen, R. Sensory and rheological characterization of acidified milk drinks. Food Hydrocolloids 2008, 22, 798-806.

7. Xue, J.; Ngadi, M. Effects of methylcellulose, xanthan gum and carboxymethylcellulose on thermal properties of batter systems formulated with different flour combinations. Food Hydrocolloids 2009, 23, 286-295.

8. Akindbode, A.A.; Ngadi, M.O. Microstructural properties of deep-fat fried chicken nuggets coated with different batter formulation. International Journal of Food Properties 2011, 14 (1), 68-83.

9. Keller, J.D. Sodium carboxymethylcellulose (CMC). In: Food Hydrocolloids, Vol. 3; Glicksman, M.; Ed.; CRC Press, Inc.: Boca Raton, FL, 1982; 43-110.

10. Campos, C.A.; Gerschenson, L.N.; Flores, S.K. Development of edible films and coatings with antimicrobial activity. Food and Bioprocess Technology 2011, 4, 849-875.

11. Amboon, W.; Tulyathan, V.; Tattiyakul, J. Effect of hydroxypropyl methylcellulose on rheological properties, coating pickup, and oil content of rice flour-based batters. Food Bioprocess Technology 2012, 5, 601-608.

12. Grover, J.A. Methylcellulose (MC) and hydroxypropylmethylcellulose (HPMC). In: Food Hydrocolloids, Vol. 3; Glicksman, M.; Ed.; CRC Press, Inc.: Boca Raton, FL, 1982; 121-156.

13. Sabanis, D.; Tzia, C. Selected structural characteristics of HPMC-containing gluten free bread: A response surface methodology study for optimizing quality. International Journal of Food Properties 2011, 14 (2), 417-431.

14. Rosell, C.M.; Rojas, J.A.; Benedito de Barber, C. Influence of hydrocolloids on dough rheology and bread quality. Food Hydrocolloids 2001, 15, 75-81.

15. Barcenas, M.E.; Rosell, C.M. Different approaches for increasing the shelf life of partially baked bread: Low temperatures and hydrocolloid addition. Food Chemistry 2006, 100, 1594-1601.

16. Rosell, C.M.; Foegeding, A. Interaction of hydroxypropilmethylcellulose with gluten proteins: Small deformations properties during thermal treatment. Food Hydrocolloids 2007, 21, 1092-1100.

17. Bárcenas, M.E.; De la O-Keller, J.; Rosell, C.M. Influence of different hydrocolloids on major wheat dough components (gluten and starch). Journal of Food Engineering 2009, 6, 241-247.

18. Armero, E.; Collar, C. Anstistaling additives, flour type and sourdough process effects on functionality of wheat doughs. Journal of Food Science 1996, 61, 299-303. 
19. Dodić, J.; Pejin, D.; Dodić, S.; Popov, S.; Mastilović, J.; Popov-Raljić, J.; Zivanovic, S. Effects of hydrophilic hydrocolloids on dough and bread performance of samples made from frozen dough. Journal of Food Science 2007, 72, 235-241.

20. Angioloni, A.; Collar, C. Gel, dough and fibre enriched fresh breads: Relationships between quality features and staling kinetics. Journal of Food Engineering 2009, 91, 526-532.

21. Correa, M.J.; Añón, M.C.; Perez, G.T.; Ferrero, C. Effect of modified celluloses on dough rheology and microstructure. Food Research International 2010, 43, 780-787.

22. ASTM International. Monograph D1347-72. In: Test Methods for Methylcellulose; American Society for Testing and Materials Monographs: West Conshohocken, PA, 1995.

23. AACC International. Methods 54-21, 38-12, 44-19. In: Approved Methods of the American Association of Cereal Chemists, 10th Ed.; The American Association of Cereal Chemists, Inc.: St. Paul, MN, 2000.

24. Ribotta, P.D.; Le Bail, A. Thermo-physical and thermo-mechanical assessment of partially baked bread during chilling and freezing process. Impact of selected enzymes on crumb contraction to prevent crust flaking. Journal of Food Engineering 2007, 78, 913-921.

25. Guarda, A.; Rosell, C.M.; Benedito, C.; Galotto, M.J. Different hydrocolloids as bread improvers and antistaling agents. Food Hydrocolloids 2004, 18, 241-247.

26. Attenburrow, G.E.; Goodband, R.M.; Taylor, L.J.; Lillford, P.J. Structure, mechanics and texture of a food sponge. Journal of Cereal Science 1989, 9, 61-70.

27. Champion, D.; Le Meste, M.; Simatos, D. Towards an improved understanding of glass transition and relaxations in foods: Molecular mobility in the glass transition range. Trends in Food Science and Technology 2000, 11, 41-55.

28. Johari, G.P. Glass transition and secondary relaxations in molecular liquids and crystals. Annals of New York Academic Science 1976, 279, 117-140.

29. Scandola, M.; Ceccorulli, G.; Pizzoli, M. Molecular motions of polysaccarides in the solid state: Dextran, pullulan and amylose. International Journal of Biological Macromolecules 1991, 13, 254-260.

30. Bárcenas, M.E.; Rosell, C.M. Effect of HPMC addition on the microstructure, quality and aging of wheat bread. Food Hydrocolloids 2005, 19, 1037-1043.

31. Armero, E.; Collar, C. Crumb firming kinetics of wheat breads with anti-staling additives. Journal of Cereal Science 1998, 28, 165-174.

32. León, A.; Durán, E.; Benedito de Barber, C. A new approach to study starch changes occurring in the dough-baking process and during bread storage. Zeitschrift für Lebensmittel Untersuchung und Forschung 1997, 204, 116-120. 